\title{
NOTAS SOBRE A APATIA POLÍTICA DO POVO ATENIENSE DURANTE O GOLPE OLIGÁRQUICO QUE DERRUBOU A DEMO- CRACIA ATENIENSE EM 411 / 410 A.C.
}

\author{
Prof. Doutorando Félix Jácome Neto ${ }^{1}$
}

\begin{abstract}
Resumo: Este artigo discute a falta de ação coletiva do povo ateniense ( $\delta \tilde{\eta} \mu \circ \varsigma_{)}$ para defender a sua democracia durante os eventos que levaram ao golpe oligárquico de 411 / 410 a.C. No livro oitavo da sua História da Guerra do Peloponeso, Tucídides afirma que o povo ateniense não protestou coletivamente contra o oligarcas quando a Assembleia decretou a sua própria dissolução depois de ter mudado a constituição política da democracia para um governo de Quatrocentos membros. A violência política que Tucídides atribui aos oligarcas é vista pela historiografia hegemônica sobre o tema como a razão principal que explica a apatia do povo ateniense quando ocorreu o golpe. Uma outra interpretação desses acontecimentos, contudo, acusa o $\delta \tilde{\eta} \mu \circ \varsigma_{\text {de }}$ ter sido cúmplice dos oligarcas em relação à mudança da constituição. $\mathrm{O}$ povo ateniense, neste caso, seria pouco fiel à democracia e colocaria o dinheiro persa por cima da democracia. Este artigo debate estas interpretações e reforça a necessidade de uma abordagem sociológica para este problema da ação coletiva do $\delta \tilde{\eta} \mu \mathrm{o}$. $\mathrm{O}$ artigo salienta, ainda, a necessidade de estudar uma ferramenta de propaganda da oligarquia: a ideia de que a única maneira de salvar Atenas seria mudar o regime político. $\mathrm{Na}$ verdade, o léxico da salvação da cidade aparece repetidamente nos discursos das personagens oligárquicas, sendo que esta propaganda sistemática também contribuiu para a desmobilização coletiva do povo ateniense durante os primeiros eventos do golpe oligárquico que derrubou, pela primeira vez, a democracia ateniense.
\end{abstract}

Palavras chaves: Democracia ateniense; Tucídides; Oligarquia.

Um dos critérios mais pertinentes para delimitarmos o começo da democracia na Grécia Antiga reside na presença de uma ação política autônoma e coletiva por parte do $\delta \tilde{\eta} \mu \mathrm{o}$, entendido como os grupos sociais que não pertenciam à elite no quadro das emergentes cidades-estados da Grécia. A partir deste referencial, as primeiras açôes do $\delta \tilde{\eta} \mu \mathrm{s}$ de que temos notícia na história da cidade de Atenas, a mais bem documentada cidade do mundo grego, ocorreram no contexto do golpe político por Cílon em uma data 
que oscila entre 636/5 a 628/72; nos conflitos sociais entre proprietários de terras e camponeses com pouca ou mesmo nenhuma terra que são visíveis no período do arcontado de Sólon no ano de 594/3 e, mais significativamente, na crise política que culminou nas reformas de Clístenes em 508/7. $\mathrm{O}$ fato de as leis atribuídas a Sólon e das reformas lideradas por Clístenes terem acarretado mudanças institucionais significa que a ação política do $\delta \tilde{\eta} \mu \varsigma_{\zeta}$ adquiriu expressão, ainda que parcial, na vida institucional da cidade. As reformas de Clístenes em 508/507, além disto, foram o resultado de uma movimentação política do povo de Atenas que, ainda que tenha existido antecedentes nos eventos mencionados, atingiu uma amplitude e uma clareza política sem precedentes, de sorte que podemos muito bem considerar que "a ação demótica" dos anos em torno de 508/507 inaugura a democracia ateniense.

Uma das principais fontes históricas sobre a turbulência política dos anos de 508/507 consiste no livro quinto de Heródoto. ${ }^{4} \mathrm{O}$ escritor de Halicarnasso nos conta que, após o fim das tiranias atenienses em 510, dois líderes lutavam pelo poder na cidade: Clístenes e Iságoras, ambos oriundos de famílias aristocráticas. A balança da luta política pendia em favor de Clístenes, quando, segundo Heródoto, Iságoras elaborou um contragolpe: ele enviou um arauto para convencer os atenienses de que Clístenes e seus seguidores deveriam ser banidos da cidade, uma vez que a família dele era amaldiçoada, o que acabou por forçar Clístenes a exilar-se $(\text { V 70) })^{5}$ Com o auxílio do rei espartano Cleomenes, Iságoras baniu centenas de famílias de atenienses da cidade (possivelmente simpatizantes de Clístenes) e, em seguida, tentou abolir o Conselho e transferir o governo da cidade para trezentos pessoas com possível afinidade política (V 72.1). ${ }^{6}$

Eis que, então, surge um novo agente político no relato de Heródoto, que altera a coloração dos conflitos sociais até então geralmente concernentes às famílias nobres:

Mas quando o Conselho resistiu e recusou a obedecer, Cleomenes, Iságoras e seus companheiros ocuparam a Acrópole. No entanto, o

2 Todas as datas neste artigo são a.C.

3 Sobre estes acontecimentos ver Carvalho; Jácome Neto (2014) e Ferreira; Leão (2010, p. 9-29; p. $119-45)$.

4 Todas as traduções dos autores antigos bem como dos comentadores modernos neste artigo são de minha autoria. Os textos gregos que serviram de base para as traduçóes são indicados na bibliografia do artigo a partir do nome do autor.

5 A razão desta maldição é explicada por Heródoto logo em seguida (V 71).

6 Iságoras desejava um Conselho mais restrito em termos de cidadania, além do que era propenso ao governo de uma elite que fosse simpática aos espartanos. 
restante dos Atenienses, que compartilhavam um só pensamento sobre esta questão, os sitiaram por dois dias. No terceiro dia houve uma trégua e foi permitido aos Lacedemônios saírem do território (HERÓDOTO, Histórias, V, 72. 2).

Após a expulsão dos espartanos e de partidários de Iságoras, Heródoto nos diz que os atenienses pediram a volta de Clístenes e das famílias atenienses exiladas (V. 73.1). Com a recém despertada força do $\delta \tilde{\eta} \mu \mathrm{o}$, Clístenes foi hábil em usar a sua relevância social para avançar reformas que se mostraram decisivas para o advento da democracia.

Como analisa o excelente texto escrito por Ober (2007), a ação política do povo ateniense descrita por Heródoto foi um levante aparentemente espontâneo, sem líder, com um claro objetivo político de evitar o golpe levado a cabo por Iságoras e seu grupo político. Com esta ação, o $\delta \tilde{\eta} \mu \mathrm{o}$ intrometese na disputa política dentro da elite, exigindo que as suas decisóes sejam respeitadas. Neste sentido, o $\delta \tilde{\eta} \mu \mathrm{o} \zeta$ mostra a sua força, uma noção igualmente constitutiva da palavra democracia, que significa o poder do $\delta \tilde{\eta} \mu \circ \varsigma$ na medida em que existe uma força no exercício do poder. É justamente este novo protagonismo da população até então à margem da vida política das cidades aristocráticas que fomenta as condiçôes sociais e políticas para as reformas e instituições que configurarão o regime democrático no seu apogeu durante os séculos $\mathrm{V}$ e IV.

O ativismo dos setores sociais de fora da elite no episódio das reformas sociais ocorridas na última década do sexto século difere, substancialmente, da apatia política que Tucídides atribui, como veremos, aos atenienses quando o seu regime político foi pela primeira vez derrubado em 411/410. Se a "ação demótica" assinala o advento de um novo horizonte político que motivou e possibilitou o surgimento da democracia, a falta de ação política está ligada ao breve mas traumático declínio que este regime político vivenciou nestes conturbados anos de 411 e 410. Para nós modernos, acostumados com a democracia representativa, que, por definição, exige uma separação entre a massa da população e as instâncias de deliberação política, a falta de mobilização política pode nos surgir como previsível. No quadro de uma

\footnotetext{
7 Por mais que mudanças institucionais tenham sido decisivas para o advento da democracia, elas são a resultante de um processo de conflito social baseado na autonomia política de amplos setores da sociedade. Se não é uma instituição, também não é um indivíduo que funda a democracia, seja Sólon, Clístenes ou Efialtes. O elemento decisivo liga-se, antes, à ação política do $\delta \tilde{\eta} \mu \mathrm{o}$. Sobre esta questão, ver as observaçóes de Ober (1997), que reage contra leituras institucionalistas da origem da democracia como esta de Hansen (2009 [1991], 156): "A democracia radical foi instaurada pelas reformas de Efialtes de 462".
} 
democracia direta, como era o caso da Grécia Antiga, é particularmente intrigante esta passividade que Tucídides atribui ao povo, que de outra maneira era acostumado a participar ativamente da vida política da cidade de Atenas.

Este artigo pretende lançar uma reflexão sobre o papel do povo ateniense nos acontecimentos que culminaram na Assembleia que aprovou a mudança da democracia para uma oligarquia governada por Quatrocentos homens. Como bem sabem os cientistas sociais que lidam com fenômenos de ação coletiva, possíveis respostas para uma falta de ação política de um determinado setor da sociedade são multifatoriais e difíceis de estabelecer, de sorte que este artigo não pretende esgotar a questão, antes despertar o interesse de estudiosos da antiguidade ou da política contemporânea sobre como uma sociedade antiga lidou com fenômenos de golpes à democracia orquestrados por um grupo que utilizou quase qualquer meio disponível para atingir seus objetivos políticos.

$\mathrm{O}$ artigo está dividido em duas partes. Na primeira, é feita uma breve narrativa dos eventos que levaram ao golpe, que ocorreu, provavelmente, em junho de 411, quando foi instalado um novo governo com Quatrocentos membros politicamente ativos. A segunda parte, por sua vez, lida particularmente com o tema da apatia que Tucídides, nossa principal fonte antiga sobre o assunto, atribui ao $\delta \tilde{\eta} \mu o \zeta$. Nesta segunda seção é enfatizada a necessidade de o historiador da antiguidade possuir um certo embasamento sociológico de modo a construir uma narrativa mais plausível de como se comportam os indivíduos e os grupos políticos.

\section{DA CONSPIrAÇÃo OLIGÁrQUiCA À disSOLUÇão dA Assembleia popular}

O livro oitavo de Tucídides, que explora em profundidade a conexão entre a política interna ateniense e a condução exterior da guerra através de uma análise da guerra civil em Atenas trazida pelo golpe oligárquico de $411 / 410$, ${ }^{8}$ pode ser encarado como uma contraposição ao livro segundo, dedicado, entre outras coisas, ao elogio da cidade de Atenas e dos atenienses refletido no discurso fúnebre que o historiógrafo atribui a Péricles. Enquanto no discurso de Péricles uma das qualidades do regime democrático ateniense

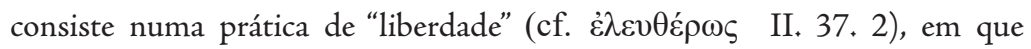
tanto na vida política como nos "hábitos cotidianos de vida" ( $\tau \tilde{\omega} v \kappa \alpha \theta$,

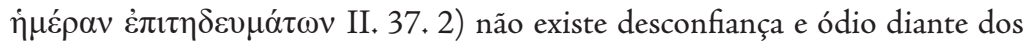

8 Cf. Connor (1984, p. 214). O livro oitavo cobre os acontecimentos da Guerra do Peloponeso entre os anos de 413 e 411. 
outros cidadãos, no clima social ateniense vigente durante os episódios que alimentaram o golpe oligárquico, ao contrário, "dentre o povo, pois, todos se abordavam com suspeitas, com receio de que o outro possa ter tido parte nos acontecimentos" (VIII. 66. 5). Essa "desconfiança do povo em relação a si

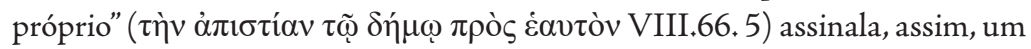
índice de diferença entre a democracia sob a liderança de Péricles, elogiada no discurso fúnebre, e a instável democracia dos anos seguintes à expedição contra a Sicília. A cidade de Atenas do discurso de Péricles, pensada como una e indivisível, é exposta, no livro oitavo, à fragmentação política e às lutas internas em torno de facções que rivalizam pelo controle político da cidade. O conflito, assim, rompe a idealização de uma Atenas sem dissenso, uma idealização que foi típica de discursos cívicos que elogiavam a unidade da cidade em torno da democracia, como, por exemplo, a oração fúnebre de Péricles. ${ }^{9}$

Tucídides narra os episódios concernentes ao golpe de 411/410 especialmente entre os capítulos 45 e 98 do livro oitavo. A causa imediata do golpe de acordo com o historiógrafo é dupla: 1 - existia o desejo do político ateniense Alcibíades em retornar para Atenas após ter fugido da cidade acusado de impiedade no caso da profanação de rituais religiosos no ano de 415. ${ }^{10}$ Alcibíades imaginava, nos diz Tucídides, que um regime oligárquico seria mais favorável ao seu regresso do que a democracia que o processara alguns anos antes por conta dos eventos de 415 (VIII 47). 2 - havia, ainda, uma movimentação política de descontentes com a democracia de caráter oligárquico no interior de Atenas que é particularmente visível nas nossas fontes a partir de 415, justamente o ano em que ocorreram os incidentes da profanação dos Mistérios e da mutilação das estátuas de Hermes que parte considerável da opinião pública ateniense interpretou como movimentos conspiratórios contra a democracia. ${ }^{11}$

9 Sobre os discursos que reforçavam a ideologia cívica da cidade de Atenas como uma unidade sem conflitos de classe, ver o magistral livro de Loraux (2006 [1981]).

10 É preciso ter em mente que a definição moderna de "agente político", isto é, uma pessoa que se dedica exclusivamente ou profissionalmente à vida política de um certo território, é estranha à democracia antiga. Todos estes políticos que mencionamos neste artigo são, também, cidadãos e militares, três elementos que eram interligados no mundo grego.

11 As estátuas do deus Hermes eram colocadas especialmente em cruzamentos de ruas como simbologia de proteção ao viajante. $\mathrm{O}$ dano que grupos de jovens causaram a estas estátuas na véspera da partida da expedição ateniense à Sicília foi visto como um ato ímpio e de mau augúrio contra a expedição a esta região. De maneira similar foi encarado o escândalo da paródia de ritos religiosos que ocorreu em algumas casas de atenienses. Estes ritos eram reservados apenas aos iniciados e não deveriam, portanto, ser apresentados para uma pessoa não-iniciada. A gravidade destes eventos pode ser sentida pela forte reação jurídica que a democracia colocou em marcha para punir os envolvidos, um deles sendo precisamente Alcibíades, que então se exilou para fugir a uma punição mais severa. Sobre este assunto ver McGlew (1999), que é particularmente elucidativo sobre a repercussão política destes eventos religiosos, e Leão (2004). 
Estas duas linhas de força contra a democracia juntam-se em novembro e dezembro do ano de 412. Alcibíades faz chegar a sua vontade política a uma importante armada naval ateniense que se encontrava na ilha de Samos, próxima ao que hoje é a Turquia. ${ }^{12}$ Alcibíades diz aos marinheiros em Samos que ele conversou com Tissafernes, o sátrapa responsável por parte da Ásia Menor sob o domínio do reino Persa, que teria concordado em ajudar financeiramente Atenas contra Esparta desde que o regime dos atenienses fosse substituído por um outro governo administrado por um grupo reduzido de pessoas simpáticas aos Persas. Em Samos, Alcibíades encontra um terreno fértil entre uma parcela dos homens mais influentes da armada para a derrubada da democracia. Os

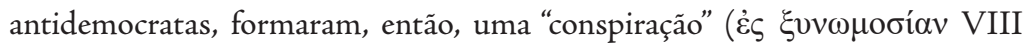
48.2) para trazer Alcibíades de volta à Atenas e para "abolir a constituição

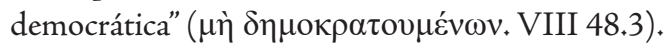

Uma das primeiras iniciativas deste grupo recém formado de opositores do regime democrático foi enviar uma delegação à Atenas liderada por um político chamado Pisandro ${ }^{13}$. O objetivo desta embaixada, nos diz Tucídides, foi "trabalhar pelo retorno de Alcibíades assim como pela derrubada da democracia na cidade, buscando, desse modo, trazer a amizade de Tissafernes aos Atenienses" (VIII 49) ${ }^{14}$. Pisandro chegou em Atenas provavelmente até o início de janeiro de $411^{15}$. Apesar de Tucídides dar a impressão de que Pisandro discursou aos atenienses logo em seguida à sua chegada à Atenas (VIII 53),

12 Atenas tinha destacado parte da sua marinha para conter rebeliões de cidades aliadas. Nesse momento ocorreu uma revolta popular em Samos que justificou a ida da marinha para este local, um fato que não é sem interesse para este artigo: os atenienses foram ajudar o $\delta \tilde{\eta} \mu \circ \zeta$ de

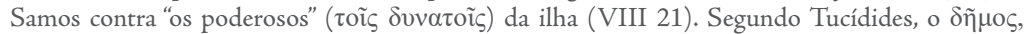
aqui entendido como os setores de fora da elite, matou aproximadamente 200 membros destes poderosos, exilou outros 400 , confiscou as suas propriedades, assumiu a "administração da cidade" ( com um homem rico! Esse tipo de alinhamento de parte da população de uma cidade grega com Atenas contra uma outra parte da população (nobre) da mesma cidade foram recorrentes durante a Guerra do Peloponeso e servia, claro, tanto para fomentar a disputa de classes no interior de uma cidade grega como para fortalecer o domínio de Atenas na geopolítica grega. Sobre este assunto ver o excelente artigo de De Ste. Croix (1954).

13 Pisandro aparentemente foi um político recém convertido à causa oligarca, dado que temos registros de suas atividades políticas anteriores a 411 como um apoiador da democracia, tendo, inclusive, participado da acusação realizada pela cidade contra os indivíduos que destruíram as estátuas de Hermes. Sobre a carreira política de Pisandro, ver Woodhead (1954), que enxerga uma mudança sincera de posicionamento político de democrata para oligarca devido à pressão da Guerra do Peloponeso sobre a maneira de administrar a cidade de Atenas.

14 É discutível até que ponto trata-se de uma embaixada "oficial" eleita pelos soldados atenienses em Samos ou de uma autoproclamada embaixada que trabalhou às margens do interesse do restante da armada de Samos.

15 Cf. Andrewes (1992, p. 472). Alguns autores recentes preferem, contudo, situar em fevereiro de 411 a chegada de Pisandro (cf. a nota escrita por Rhodes em Thucydides 2009, p. 622-23. Cf. a nota seguinte. 
ele possivelmente ainda levou um ou dois meses para anunciar publicamente o plano de alterar o regime da cidade ${ }^{16}$. Nesta ocasião os embaixadores de Samos "falaram diante do povo" apelando-os a chamarem Alcibíades de volta, estabelecendo um pacto com o Rei Persa com o qual poderiam vencer os espartanos, desde que estivessem dispostos a estabelecer "uma outra forma

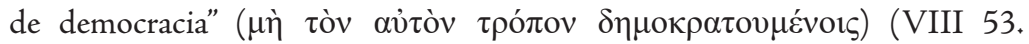
1). $\mathrm{O} \delta \tilde{\eta} \mu \mathrm{s}$ presente na Assembleia, aqui entendido como o conjunto dos cidadãos masculinos atenienses, criticou os propósitos da embaixada, tanto sobre Alcibíades como sobre a democracia, mas acabou por aceitar o envio de Pisandro e outros dez cidadãos em uma missão para negociar com Tissafernes e Alcibíades os termos de um eventual pacto com os Persas (VIII 54.3).

Tucídides adiciona um comentário muito significativo para a compreensão do ambiente político ateniense: antes de partir, Pisandro reúne-se com grupos secretos de atenienses para os quais ele exortava que se mantivessem unidos no

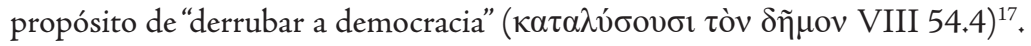
Observamos, assim, que a linguagem usada por Pisandro para anunciar os seus planos é diferente consoante os ouvintes são os atenienses reunidos em Assembleia ou estes pequenos grupos de descontentes com a democracia. Para os primeiros, Pisandro fala, como vimos, em instaurar uma outra forma de democracia, enquanto para os últimos ele usa o verbo $\kappa \alpha \tau \alpha \lambda$ particularmente estridente pois significa "abolir" ou "dissolver", enquanto

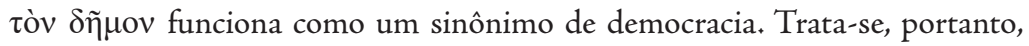

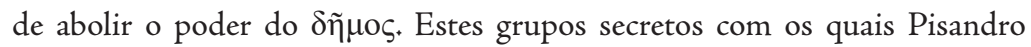
discursa de maneira tão abertamente antidemocrática eram constituídos, neste contexto, por membros da elite descontentes com a democracia, sendo que alguns dentre eles foram certamente convictos oligarcas. ${ }^{18}$

16 Uma comédia de Aristófanes, Lisístrata, encenada ao público seguramente em 411 e provavelmente no mês de fevereiro deste ano (cf. Henderson em Aristophanes 1987, p. xv-xxv), apresenta Pisandro como uma das personagens da peça, sem que haja qualquer menção aos seus planos oligárquicos ou mesmo de alteração de regime político. Se Pisandro tivesse tornado público o intento dos conjurados de modificar a constituição desde dezembro de 412 ou janeiro de 411, é implausível que uma notícia desta envergadura não tivesse influenciado a representação cômica desta figura na peça de Aristófanes. Para a cronologia da chegada de Pisandro a Atenas e do seu discurso aos atenienses, ver Andrewes et alii (1981, p. 186-193); Kagan (1987, p. 131-132).

17 Embora Tucídides diga que Pisandro articulou os grupos de opositores da democracia após uma primeira Assembleia com os atenienses, ele pode ter feito isso também entre o tempo que chegou na cidade e esta Assembleia.

18 Tucídides, nesta passagem VIII 54.4, chama estes grupos com o substantivo $\sigma v v \omega \mu$ oбía, que significa literalmente "indivíduos comprometidos sob juramento a fazer algo juntos". Esse tipo de

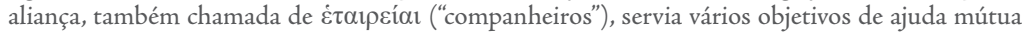
entre seus membros geralmente de estrato nobre. Este espécie de agremiação de companheiros existiu em todo o seculo quinto ateniense e muitas vezes não acarretava um significado político imediato, muito menos antidemocrático. Com o acirramento dos conflitos sociais em Atenas 
Um pouco mais adiante na sua narrativa, Tucídides testemunha o dano que a delegação de Pisandro e estes grupos secretos fizeram na vida cívica e política ateniense (VIII 65-66). Primeiro, uma campanha de espalhar o terror entre a população através, por um lado, da eliminação física de líderes democratas, que incluiu assassinatos, tanto do democrata Androcles, que Tucídides qualifica como "o maior guardião do povo" ( $\tau$ oṽ $\delta \eta ́ \mu o v ~ \mu \alpha ́ \lambda \imath \sigma \tau \alpha$ $\pi \rho 0 \varepsilon \sigma \tau \tilde{\omega} \tau \alpha$ VIII 65.2 ), bem como de outros opositores aos oligarcas, mortos secretamente, como denota o advérbio $\kappa \rho v ́ \varphi \alpha$ em VIII 65.2. Por outro lado, os grupos oligarcas passam a desconfigurar o funcionamento das Assembleias, instância decisiva da democracia ateniense, por meio de intimidações contra os cidadãos participantes das Assembleias, de sorte que, como interpreta Tucídides, o povo "consternado" ( $\alpha \tau \tau^{\prime} \pi \lambda \eta \xi \mathrm{lv}$ VIII 66.2) guardava "silêncio"

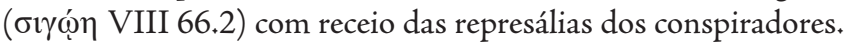

Este era o clima político da cidade quando aconteceu uma primeira Assembleia que expôs publicamente as ideias de Pisandro. Esta Assembleia é narrada por Tucídides no capítulo 67, logo em seguida, portanto, do relato sobre o temor causado na cidade pelas atividades violentas e intimidatórias dos conspiradores. $\mathrm{O}$ efeito da narrativa é claro: a mudança de regime foi aprovada pela própria instância que era até então o coração da própria democracia, por conta do ambiente dissuasivo de qualquer resistência democrática. A mudança de regime, descrita no capítulo 67, começa com a nomeação, proposta por Pisandro e aprovada pelo povo, de dez "redatores independentes" ( $\delta \varepsilon ́ \kappa \alpha$

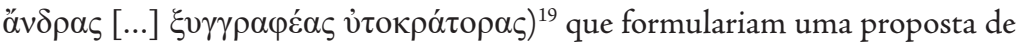

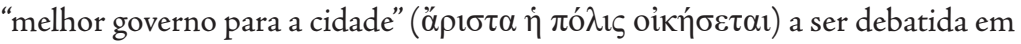
uma Assembleia dedicada ao debate deste tópico. ${ }^{20}$

durante a Guerra do Peloponeso, especialmente a partir de 415, nós temos cada vez mais informação sobre estes grupos enquanto formas de articulação política dos setores da elite desejosos em derrubar a democracia. Sobre este tema, Calhoun (1913) permanece fundamental. Connor (1971) é excelente na contextualização destes grupos na política ateniense pós-Péricles. Entre a bibliografia relativamente recente, McGlew (1999) é particularmente útil para localizar o momento histórico, por volta do ano de 415, a partir do qual estes grupos começaram a ser mais políticos e antidemocráticos.

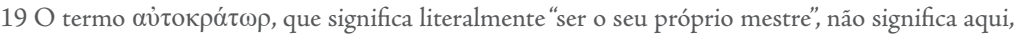
como nota Andrewes et alii (1981, p. 165), ter "plenos poderes", como por vezes se traduz a palavra, uma vez que a função desta comissão era tão-somente remeter a proposta para a decisão soberana da Assembleia. De certa forma estes redatores estavam substituindo o papel do Conselho, cujas funções incluía a preparação de temas e discussóes a serem apreciadas pela Assembleia, ainda que, bem entendido, não se esperaria do Conselho apresentar uma solução alternativa à democracia.

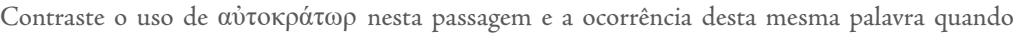
utilizada para o novo governo dos Quatrocentos, como se discutirá em seguida.

20 A obra Constituição dos Atenienses (29. 2), atribuída a Aristóteles e escrita por volta de 330, afirma que a comissão de redação da nova proposta de governo era formada por trinta membros e não dez, como afirma Tucídides. Neste ponto, os especialistas seguem antes Aristóteles do que Tucídides. 
Chegado o dia da Assembleia decisiva, provavelmente em junho de 411, os cidadãos de Atenas tomam conhecimento do resultado do trabalho dos redatores: eles propóem a anulação de uma lei do funcionamento democrático da Assembleia, nomeadamente esta que punia os oradores que propusessem ações ou medidas que fossem claramente contra a democracia. Ora, ao passo que a Assembleia era um espaço aberto no qual todos os cidadãos masculinos eram habilitados a assumir a função de orador proferindo um discurso, o cidadão, uma vez investido na qualificação ad hoc de orador, assumia responsabilidade pelo conteúdo das suas propostas. Se a proposição fosse considerada pelos presentes como anticonstitucional, o orador em questão poderia ser processado por um dispositivo jurídico chamado $\gamma \rho \alpha \varphi \eta ̀ ~ \pi \alpha \rho \alpha v o ́ \mu \omega v$, uma expressão citada especificamente por Tucídides nesta passagem VIII 67. 2. O termo $\pi \alpha \rho \alpha v o ́ \mu \omega v$ significa aquilo que passa ao lado do vó $\mu o \varsigma$, isto é, da lei, enquanto o substantivo $\gamma \rho \alpha \varphi \eta ́$ significa "escrita". Assim, qualquer cidadão presente na Assembleia poderia acusar um orador mal intencionado com as leis da cidade e escrever uma peça escrita com as razóes para o processo que era então dirigida a um colégio de arcontes da cidade. ${ }^{21}$

Pois bem, não parece difícil entender a utilidade da revogação desta lei para os intentos dos oligarcas ansiosos de mudarem a forma política de Atenas. Sem o potencial impeditivo de propostas ilegais próprio da $\gamma \rho \alpha \varphi \eta ̀ ~ \pi \alpha \rho \alpha v o ́ \mu \omega v$, os oradores poderiam propor simplesmente qualquer deliberação sem serem punidos por isso. E é efetivamente o que acontece consoante Tucídides:

A proposição, agora apresentada de maneira manifesta, postulava que os presentes cargos na atual forma de governo fossem abolidos, não existindo mais o pagamento de funções públicas pela cidade. Um comitê de cinco oficiais deveria ser eleito para presidir a eleição de outros cem cidadãos, sendo que cada um destes cem escolheria mais três membros. Assim, os Quatrocentos Cidadãos resultantes deveriam reunir-se no Conselho com poder irrestrito para governar a cidade como lhe parecer mais apropriado. Por fim, eles deveriam convocar Cinco mil cidadãos como e quando eles julgassem oportuno (TUCÍDIDES, História da Guerra do Peloponeso, VIII 67. 3 $68.1)$.

Assim, pelo teor desta proposta, as duas principais instituiçóes de discussão e deliberação da democracia ateniense, a Assembleia e o Conselho, perdem totalmente a sua função em nome de um governo composto por Quatrocentos cidadãos escolhidos, note-se bem, através de um procedimento

21 Mais detalhes sobre este procedimento por ser lido em Hansen (2009 [1991], p. 239-249). Leite (2014, p. 404) traduz a expressão como "ação pública de ilegalidade". 
restritivo e que favorecia a aglomeração de membros da mesma posição política antidemocrática.

Ainda que Pisandro e seus colegas não tenham usado a palavra oligarquia, este gênero de discurso é bem mais explícito quanto a proposição de um governo no interior do qual a participação é severamente limitada do que foram propostas anteriores de apresentar apenas uma outra forma de democracia, como vimos acima. ${ }^{22}$ Ainda assim, Tucídides nos diz que esta moção foi aprovada pela Assembleia "sem nenhum discurso contrário"

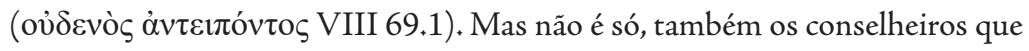
trabalhavam no Conselho aceitaram sair do recinto e ceder o espaço para o novo governo também sem protestar (VIII 70, 1). Tucídides utiliza inclusive

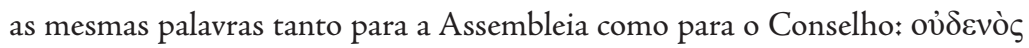

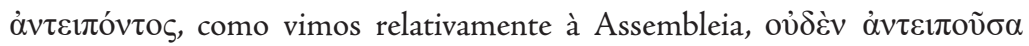
para o Conselho.

À luz da caracterização das origens da democracia apresentada no início deste artigo, esta apatia do $\delta \tilde{\eta} \mu o \zeta$, que aceita perder suas duas principais instituições democráticas, clama por explicação.

\section{INTERPRETAÇÕES SOBRE A APATIA DO $\Delta \tilde{\eta} M O \Sigma$ DURANTE A INSTAURAÇÃO DO GOLPE OLIGÁRQUICO}

A interpretação mais difundida na literatura especializada concebe esta apatia do $\delta \tilde{\eta} \mu \mathrm{\zeta}$ como uma consequência, por um lado, da atmosfera de violência e perseguição política contra os democratas promovida pelos conspiradores oligarcas - como vimos acerca dos capítulos 65 e 66 do livro oitavo - e, por outro lado, da manipulação retórica dos oligarcas que apresentaram a mudança de regime de maneira eufemística de forma a não revelar claramente as suas intenções oligarcas dos conspiradores. Kagan (1987, p. 145), por exemplo, localiza no terror provocado pelos oligarcas a chave para entender o golpe:

Há pouca dúvida de que o retrato da mudança constitucional apresentado por Tucídides, decorrente de um golpe feito por meio de terror, força e engodo, é mais credível do que a narrativa de Aristóteles de uma transição tranquila e legal. Os assassinatos, intimidaçóes e

22 A palavra oligarquia não é usada no discurso desta Assembleia, mas é utilizada a expressão

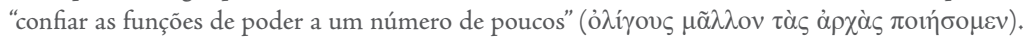
Esta expressão claramente refere para a oligarquia, como corretamente sustenta Taylor (2002, p. 97-8) contra estudiosos que minimizam o teor explicitamente oligárquico desta frase. 
outras irregularidades que Tucídides reporta são inquestionavelmente reais.

Westlake (1973, p. 199), por sua vez, comenta que quando Pisandro apresentou as propostas de mudança constitucional na Assembleia, ele fez de uma maneira que a proposição aparentasse não trazer qualquer mudança fundamental de regime. David (2014, p. 18) afirma que a "Democracia degenerou em "fobocracia" [phobocracy] $]^{23}$ - o reino do terror, com o qual os oligarcas assumiram controle pleno das instituições e comunicações políticas em Atenas".

Esta interpretação não é, contudo, unânime. Taylor (2002), por exemplo, sustenta que a historiografia dominante sobre o assunto tem posto muito peso sobre os atos ilícitos e intimidatórios dos oligarcas contra o povo ateniense e, assim, tem exonerado o $\delta \tilde{\eta} \mu o \varsigma$ da sua responsabilidade com o golpe, pois os atenienses estariam tão aterrorizados por conta das ações dos conspiradores que silenciavam diante das propostas contra a democracia, ao ponto de nem perceber adequadamente que se estava a tramar uma mudança radical de regime político. Contra esta visão, ela interpreta o $\delta \tilde{\eta} \mu \mathrm{s}$ envolvido nestes episódios como "frívolos e ignorantes, pouco apegados à sua democracia e totalmente cúmplices em sua própria perda de liberdade" (TAYLOR, 2002, p. 96) ${ }^{24}$ Nesse sentido, o texto de Tucídides "demonstra que foi bastante fácil pôr um fim à democracia e à liberdade dos atenienses" (TAYLOR, 2002, p. 94).

A estudiosa sustenta, assim, que a historiografia sobre este assunto tem destacado insuficientemente quanto o $\delta \tilde{\eta} \mu о \varsigma$ contribuiu, através da sua passividade, com a derrubada da democracia em 411. A autora elenca cinco oportunidades que o povo ateniense teve para conter o golpe antes que ele efetivamente se realizasse: 1 - Em Samos, quando houve a circulação das ideias de Alcibíades de conseguir o apoio Persa e minar a democracia; 2- quando a embaixada liderada por Pisandro discursou pela primeira vez em Atenas, anunciando a ideia do retorno de Alcibíades e da ajuda Persa como maneira de vencer a guerra contra Esparta a custo de estabelecer "uma outra forma de democracia"; 3 - durante o processo de intimidação e assassinato de líderes democráticos pelos conjurados oligarcas; 4- na Assembleia de junho de 411

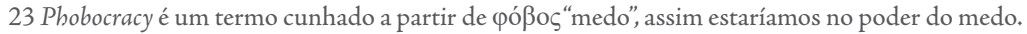
Uma leitura similar a esta que sublinha a paralisia do povo ateniense causada pelas atividades oligarcas pode ser lida, por exemplo, em Forsdyke (2005, p. 181-204).

24 Esta frase de Taylor é dirigida, a bem da verdade, especificamente à parte de fora da elite da armada que estava em Samos, mas parece representar a visão da autora sobre o comportamento do povo ateniense em geral durante o episódio. 
que votou pela mudança de regime e pela sua própria dissolução; 5- durante a tomada do Conselho pelo recém criado novo governo.

Não obstante o fato de que o artigo de Taylor é muito bem fundamentado em relação ao texto de Tucídides e tem razão em acusar estes cinco momentos de omissão política do povo ateniense, falta a autora um embasamento sociológico mais frutífero para explicar esta apatia do $\delta \tilde{\eta} \mu o \varsigma$. Um sintoma desta carência é o fato de a autora conferir uma importância exagerada à afirmação de Tucídides de que o conjunto da armada de Samos ficou tranquila ao saber dos planos de derrubar a democracia porque com apoio persa teriam os seus salários pagos (VIII 48, 2-3). Nessa leitura, o povo ganancioso e desdenhoso da democracia ficou inerte quando o regime foi derrubado e assim estaria explicada esta questão.

Uma elucidação mais sociologicamente elaborada foi oferecida recentemente por Teegarden (2012). A chave para o entendimento do papel dos atenienses no golpe reside, segundo ele, num "problema de coordenação revolucionária”. Partindo das premissas da Teoria da Escolha Racional aplicada ao entendimento das ações coletivas, nomeadamente através do teórico Kuran (1991), Teegarden comenta como, em certas circunstâncias, um indivíduo pode discordar de um sistema político mas ainda assim preferir não se opor publicamente a ele, por considerar que os custos pessoais de tal engajamento público são demasiado altos. Quando muitos indivíduos pensam desta maneira, nós temos o paradoxo do "problema de coordenação": muitos sentem-se insatisfeitos com o sistema político vigente, mas preferem guardar para o foro privado este descontentamento. Se os custos de "falsificar publicamente" o seu posicionamento começar a ser elevado, seja porque algum macro acontecimento tornou mais plausível e menos danosa uma crítica aberta ao regime ou porque muitas outras pessoas começam a expor publicamente a sua insatisfação, então há um encontro entre o descontentamento cognitivo do indivíduo e a sua expressão pública e coletiva. ${ }^{25}$

25 O título do artigo de Kuran (1991) começa com as expressivas palavras "Now Out of Never" ("Agora a partir do Nunca"). A base empírica da teorização de Kuran consiste nas manifestações ocorridas no Leste Europeu em 1989 que culminaram na queda do Bloco Soviético. "Agora a partir do Nunca" porque, ele argumenta, muitos analistas sociais foram incapazes de prever que um acontecimento dessa envergadura tivesse lugar e, à época, não se compreendia de onde tinham vindo tantos manifestantes contrários aos governos socialistas. Kuran explica a questão através do "problema de coordenação revolucionária" que estamos evocando. Uma situação não muito distante, penso, acontece atualmente no Brasil, quando, a partir das grandes manifestações de rua de 2013 a conjuntura política e econômica do país ficou muito mais favorável à expressão pública de insatisfaçóes contra o governo do Partido dos Trabalhadores. Uma das características destes levantes de 2013 a 2016, ano da queda da presidente Dilma Rousseff, foi justamente a presença assinalável de pessoas, muitas de classe média, que não tinham qualquer experiência 
Para Teegarden (2012), o $\delta \tilde{\eta} \mu \mathrm{s}$ encontrou-se com um "problema de coordenação": a maioria dos atenienses apoiava individualmente a democracia mas não agiu coletivamente para defendê-la. $\mathrm{O}$ custo de contrariar publicamente os oligarcas pareceu demasiado alto devido às represálias que já foram mencionadas. Por outro lado, a ênfase dos oligarcas na necessidade de ajuda Persa pode ter convencido certos indivíduos de que os seus colegas de democracia julgariam plausível a justificativa e aceitariam as mudanças na lei, inibindo, mais uma vez, a ação coletiva democrática (Teegarden 2012, p. 441).

O cenário muda, sustenta corretamente o autor, com alguns eventos significativos que foram capazes de alterar a equação da falta de mobilização e levaram a superação do impasse na ação do $\delta \tilde{\eta} \mu o \varsigma$. Um dos principais foi o assassinato de Frínico - um dos líderes do movimento oligárquico e suspeito de tramar uma invasão de Esparta contra Atenas - em plena praça pública de Atenas (VIII 92. 2) ${ }^{26}$. Segundo o próprio Tucídides, depois deste evento, a divergência interna entre os Quatrocentos cresceu exponencialmente, bem como a resistência dos atenienses contra o novo governo: "não era mais possível

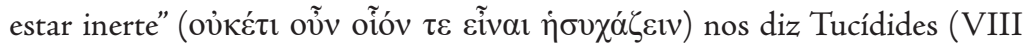
92. 3). Tucídides passa a narrar o contragolpe dos democratas que, tanto em Samos como em Atenas, reagiram e derrubaram os Quatrocentos, instalando um governo de Cinco mil membros com direito à participação política que, ele também, duraria pouco até a reinstalação da democracia plena em $410 .{ }^{27}$

Teegarden segue, a meu ver, a direção correta para explicar os acontecimentos de 411/410. Penso, todavia, que de forma a compreender a conjuntura política do golpe, um aspecto específico do programa político dos oligarcas merece mais atenção. Refiro-me à ideia de "salvação" ( $\sigma \omega \tau \eta \rho i ́ \alpha)$ de Atenas, que foi repetida várias vezes pelos oligarcas em contexto de debate político consoante a narrativa de Tucídides.

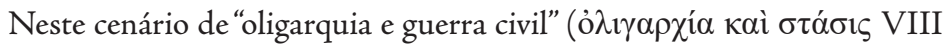
98.4) vivido em Atenas é possível perceber na narrativa de Tucídides algumas palavras chaves que dariam forma aos discursos e programas políticos que

com mobilizações públicas e políticas (cf. a coletânea de ensaios organizada por Demier; Hoeveler 2016).

26 Sobre a plausibilidade da ala mais extrema do movimento oligárquico conciliar o seu poder com Esparta, a grande inimiga de Atenas, ver Kagan (1987, p. 190-93).

27 Os eventos que conduziram ao retorno da democracia são, obviamente, de grande relevância para a superação deste estado de apatia do $\delta \tilde{\eta} \mu o s$. Por falta de espaço, contudo, limito-me a discutir as razôes da desmobilização e não propriamente os motivos que levaram à ação coletiva posterior ao golpe. Para uma boa narrativa dos acontecimentos pós-golpe que resultaram no restabelecimento da democracia, ver Andrewes (1992); Kagan (1987, 177-273). 
almejavam propor soluções à difícil conjuntura política e militar que se seguiu à expedição à Sicília. ${ }^{28} \mathrm{O}$ léxico em discussão, $\sigma \omega \tau \eta p i ́ \alpha$, é justamente uma dessas palavras que tinha lugar de destaque no vocabulário político do momento. De fato, como vimos, a retórica da facção oligárquica em 411 consistia em afirmar que a única possibilidade de salvação de Atenas estava ligada ao apoio financeiro dos persas, que, segundo a versão dos oligarcas, exigiam para tanto a mudança de regime em Atenas: da democracia para um governo em que poucos dominassem e fossem de confiança dos persas (cf. VIII 52-54).

Assim sendo, Pisandro explica para o povo que "não existia outra forma

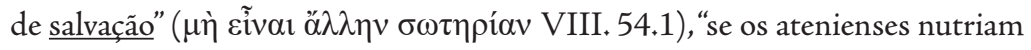

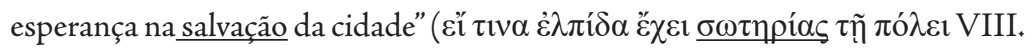
53. 2). O léxico aparece, ainda, quando Pisandro urge os cidadãos atenienses a

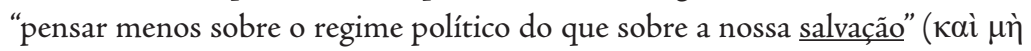

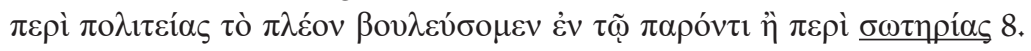
53.3).

Bieler (1951) mostrou que o tema da salvação nesta época não era supérfluo ou meramente passageiro, antes formava um slogan político que foi explorado pelos oligarcas na sua luta no interior da política ateniense e na consequente repercussão destas mudanças de regime para a postura de Atenas diante das outras cidades no quadro da Guerra do Peloponeso. Assim, a ideia reiterada pelos oligarcas de que os atenienses deveriam pensar mais na salvação da cidade do que no regime político certamente contribuiu para a falta de iniciativa do $\delta \tilde{\eta} \mu \circ \varsigma$ para defender a democracia. Se a cidade precisava ser salva, então os atenienses deveriam confiar a prerrogativa da ação política, isto é, as deliberações sobre o destino da cidade, para um grupo de especialistas que saberiam como salvá-la da derrota na Guerra do Peloponeso. Com isso, a reiteração de que esta era a única maneira de salvação levou a uma convergência com a lógica oligárquica de pensar a vida política, fortalecendo a união dos grupos antidemocráticos e enfraquecendo a capacidade de resposta por parte de um $\delta \tilde{\eta} \mu \mathrm{s}$ duplamente aterrorizado: pela violência política dos conspiradores e pela iminência de desastre total da cidade face às forças espartanas. ${ }^{29}$

28 Como destaca Davies (1993, p. 117), os anos de 413 a 411 foram decisivos para o contexto da Guerra do Peloponeso: Atenas perdeu a hegemonia no mar Egeu, Esparta agora tinha uma frota naval e os Persas estavam cada vez mais envolvidos financeiramente na guerra.

29 Por violência política eu entendo "as manifestações de ação coletiva que envolvem uma grande força física e que causa danos para um adversário com o intuito de obter ganhos políticos" (Della Porta 2001, p. 208). Este tipo de violência, como nota a mesma autora, utiliza geralmente meios ilegais de ação e, algumas vezes, concentra-se em grupos que praticam a violência de maneira clandestina. Embora seja um conceito formulado a partir da experiência política do século XX, é 
As atividades celebrativas da democracia que tiveram lugar após a restauração da democracia em 410, incluindo honras públicas aos assassinos que mataram o oligarca Frínico, mostra que a experiência traumática destes anos de 411/410 contribui para reanimar a identidade democrática, que foi mais uma vez posta à prova quando em 404 Atenas viveu outro golpe de natureza oligárquica. ${ }^{30}$ Este embate entre democratas e oligarcas nas últimas décadas do século quinto evidenciou a emergência de princípios antagônicos como soluções para a salvação da cidade: um governo destituído de Assembleia e formado por uma minoria tida como mais apta a gerir os assuntos públicos, ou um governo baseado na Assembleia que não representa o povo, pois ela própria é o povo em ação. ${ }^{31}$ Uma repetição, certamente dolorosa, da contínua disputa entre oligarcas e democratas que iniciou na passagem do sistema aristocrático para o democrático e que ainda encontrará eco nas grandes obras de filosofia política do século IV, nomeadamente estas escritas por Platão e Aristóteles.

\section{NOTES SUR L'APATHIE POLITIQUE DU PEUPLE ATHÉNIEN PENDANT LE COUP D'ÉTAT OLIGARCHIQUE QUI A EU LIEU À ATHÈNES EN $411 / 410$ AV. J.C.}

Résumé: Cet article examine le manque d'action collective du peuple d'Athènes $(\delta \tilde{\eta} \mu \circ \varsigma)$ pour défendre sa démocratie au cours des événements qui ont conduit au coup d'État oligarchique de 411/410 avant J. C. Dans le huitième livre de La guerre du Péloponnèse, Thucydide affirme que le $\delta \tilde{\eta} \mu$ o n'a pas protesté collectivement contre les oligarques lorsque l'Assemblée a décrété sa propre dissolution après avoir changé la constitution politique de la démocratie pour un gouvernement de Quatre cents membres. La violence politique qui Thucydide attribue aux oligarques est vu par l'historiographie hégémonique sur le sujet comme la raison principale qui explique l'apathie du peuple d'Athènes lors du coup d'État. Une autre interprétation de ces événements, cependant, accuse le $\delta \tilde{\eta} \mu \mathrm{\varsigma}$ d'avoir été complice des oligarques par rapport au changement de la constitution. Le peuple athénien, dans ce cas, serait peu fidèle à la democratie et situerait l'argent Perse au-dessus de la démocratie. Cet article discute ces interprétations et renforce la nécessité d'une approche sociologique sur cette problématique de l'action collective du $\delta \tilde{\eta} \mu \mathrm{o}$. Larticle souligne la nécessité d'étudier un outil de propagande de l'oligarchie: l'idée que la seule façon de sauver Athènes serait changer le régime politique. En fait, le lexique du salut de la cité apparaît à plusieurs reprises dans les discours des personnages oligarchiques et cette propagande systématique a également contribué à la démobilisation collective du peuple athénien pendant les premiers événements du coup d'État oligarchique qui a renversé pour la première fois la démocratie athénienne.

Mots-clés: Démocratie athénienne; Thucydide; Oligarchie.

notória a semelhança com o que vimos acerca dos grupos oligarcas em 411/410.

30 Sobre este tópico, ver Teegarden (2012).

31 Sobre a Assembleia como o povo em ação ver Villacèque (2012). 


\section{REFERÊNCIAS}

Documentação Textual

ARISTOPHANES. Lysistrata. Edited with introduction and commentary by Jeffrey Henderson. Oxford: Clarendon Press, 1987.

ARISTOTELES, Athenaion Politeia. Edited by M.H. Chambers. Leipzig: Teubner, 1986.

HERODOTI. Historiae, volume II: libri V-IX. Edited by C. Hude. Oxford: Clarendon Press, 1927.

THUCYDIDES. Historiae. Edited by H..S Jones; J.E. Powell. Oxford: Clarendon Press, 1942.

THUCYDIDES. The Peloponnesian War. Translated by Martin Hammond with an Introduction and Notes by p. J. Rhodes. Oxford: Oxford University Press, 2009.

Bibliografia

ANDREWES, A. et alii (orgs). A Historical Commentary on Thucydides volume V, Book VIII. Oxford: Clarendon Press, 1981.

ANDREWES, A. The Spartan resurgence. In: LEWIS, D.M. et alii (orgs). The Cambridge Ancient History. $2^{\circ}$ ed. Volume V. The Fifth Century B.C. Cambridge: Cambridge University Press, 1992, p. 464-498.

BIELER, L. A Political Slogan in Ancient Athens. American journal of Philology v. 72, n. 2, 1951, p. 181-184.

CALHOUN, George M. Athenian Clubs in Politics and Litigation. Austin: The University of Texas Bulletin, 1913.

CARVALHO, Sofia; JÁCOME NETO, Félix. A crise social na Atenas de Sólon e o estabelecimento da justiça baseada no governo da lei. HUMANITAS v. 66, 2014, p. 59-85.

CONNOR, W.R. The new Politicians of fifth-century Athens. Indianapolis; Cambridge: Hackett, 1971.

. Thucydides. Princeton: Princeton University Press, 1984

DAVIES, J.K. Democracy and Classical Greece. $2^{\circ}$ ed. London: Fontana Press, 1993.

DAVID, Ephraim. An Oligarchic Democracy: Manipulation of Democratic Ideals by Athenian Oligarchs in 411 BC. EIRENE v. 50, n. 1-2, 2014, p. 11-38.

DELLA PORTA, Donatella. Terror Against the State. In: NASH, Kate; SCOTT, Alan. The Blackwell Companion to Political Sociology. Oxford: Blackwell, 2001, p. 208-216.

DEMIER, Felipe; HOEVELER, Rejane (orgs). A Onda Conservadora: Ensaios Sobre os Atuais Tempos Sombrios no Brasil. Rio de Janeiro: Mauad, 2016

DeSTE.CROIX.G.E.M. The character of Athenian Empire. Historia:Zeitschrift für Alte Geschichte v. 3, n.1, 1954, p. 1-41.

FERREIRA, José R.; LEÃO, Delfim. F. Dez grandes estadistas atenienses. Lisboa: Edições 70, 2010. 
FORSDYKE, Sara. Exile, Ostracism, and Democracy: The Politics of Expulsion in Ancient Greece. Princeton: Princeton University Press, 2005.

HANSEN, Mogens H. La Démocratie athénienne à l'époque de Démosthène. Structure, principes et idéologie. Traduction de Serge Bardet avec le concours de Philippe Gauthier. Paris: Tallandier, 2009 [1991].

KAGAN, Donald. The Fall of the Athenian Empire. London: Cornell University Press, 1987.

KURAN, Timur. Now Out of Never: The Element of Surprise in the East European Revolution of 1989. World Politics. v. 44, n. 1, 1991, p. 7-48.

LEÃO, Delfim F. Matéria Religiosa: Processos de Impiedade (Asebeia). In: LEÃO, Delfim F. et alii (orgs). NOMOS. Direito e Sociedade na Antiguidade Clássica. Coimbra: Imprensa da Universidade de Coimbra, 2004, p. 201-226.

LEITE, Priscilla G. Ética e retórica forense: Asebeia e Hybris na caracterização dos adversários em Demóstenes. Coimbra: Imprensa da Universidade de Coimbra, 2014.

LORAUX, Nicole. The Invention of Athens: The Funeral Oration in the Classical City. Translated by Alan Sheridan. New York: Zone Books, 2006 [1981]

MCGLEW, James F. Politics on the Margins: The Athenian 'Hetaireiai' in 415 B.C. Historia: Zeitschrift für Alte Geschichte v. 48, n. 1, 1999, p. 1-22.

OBER, Josiah. Revolution Matters: Democracy as Demotic Action (A Response to Kurt A. Raaflaub). In: MORRIS, Ian; RAAFLAUB, Kurt (orgs). Democracy 2500? Questions and Challenges, 1997, p. 67-85.

"I Besieged That Man": Democracy's Revolutionary Start. In:

OBER, Josiah et alii. Origins of Democracy in Ancient Greece. Berkeley: University of California Press, 2007, p. 83-104.

TAYLOR, Martha C. Implicating the Demos: A Reading of Thucydides on the Rise of the Four Hundred. The Journal of Hellenic Studies, V. 122, 2002, p. 91-108.

TEEGARDEN, David A. The Oath of Demophantos, Revolutionary Mobilization, and The preservation of The Athenian Democracy. Hesperia: The Journal of the American School of Classical Studies at Athens. v. 81, n. 3, 2012, p. 433-465.

VILLACÈQUE, Noémie. Chahut et délibération. De la souveraineté populaire dans l'Athènes classique. Participations v. 2, n. 3, 2012, p. 49-69.

WESTLAKE, Henry D. The Subjectivity of Thucydides: his treatment of the Four Hundred at Athens. Bulletin of the John Rylands Library, v. 56, 1973, p. 193-218.

WOODHEAD, A.G. Peisander. The American Journal of Philology, v. 75, n. 2, 1954, p. 131-146. 